\title{
Simulation-Optimization Modeling: A Survey and Potential Application in Reservoir Systems Operation
}

\author{
Deepti Rani • Maria Madalena Moreira
}

Received: 13 October 2008 / Accepted: 17 July 2009 /

Published online: 30 July 2009

(C) Springer Science+Business Media B.V. 2009

\begin{abstract}
This paper presents a survey of simulation and optimization modeling approaches used in reservoir systems operation problems. Optimization methods have been proved of much importance when used with simulation modeling and the two approaches when combined give the best results. The main objective of this review article is to discuss simulation, optimization and combined simulationoptimization modeling approach and to provide an overview of their applications reported in literature. In addition to classical optimization techniques, application and scope of computational intelligence techniques, such as, evolutionary computations, fuzzy set theory and artificial neural networks, in reservoir system operation studies are reviewed. Conclusions and suggestive remarks based on this survey are outlined, which could be helpful for future research and for system managers to decide appropriate methodology for application to their systems.
\end{abstract}

Keywords Simulation optimization modeling • Reservoir system operation • Linear programming $\cdot$ Dynamic programming $\cdot$ Nonlinear programming • Evolutionary computation $\cdot$ Fuzzy set theory $\cdot$ Neural networks

\section{Introduction}

A single or multiple reservoir system which is composed of various physical components including reservoirs, channels, tunnels, pipelines, pumping stations, hydropower plants, irrigation area and urban water supply systems, operates to supply water for municipal, industrial and irrigation needs, hydropower production, flood control, recreation, navigation or ecological requirements. Management of these systems from planning to operation is very challenging since the problem deals with

D. Rani $(\varangle) \cdot$ M. M. Moreira

Hydraulics and Water Resources Group, ICAAM,

University of Évora, 7000 Évora, Portugal

e-mail: deeptinatyan@yahoo.com,deepti@uevora.pt 